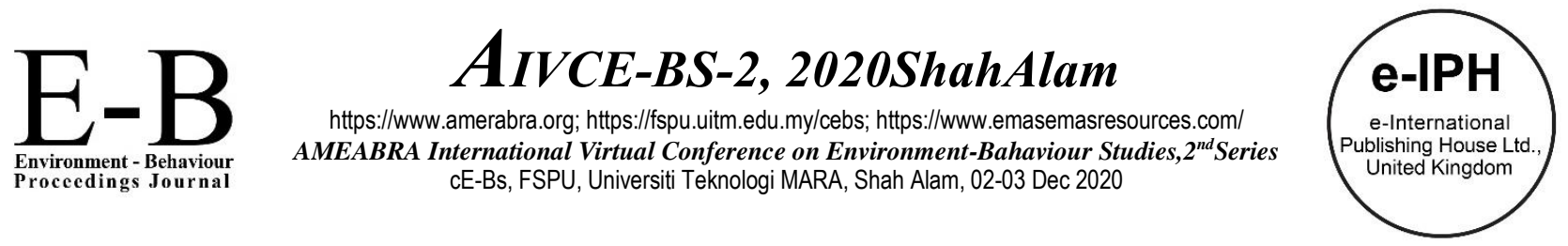

\title{
The Practice of Patient Education among Public Hospital Nurses in Malaysia
}

\author{
Norhaini Majid \\ Centre for Nursing Studies, Faculty of Health Sciences, \\ University Teknologi MARA (UiTM), Puncak Alam Campus, 42300 Bandar Puncak Alam, Selangor Darul Ehsan, MALAYSIA \\ :norhaini046@uitm.edu.my \\ Tel: 0162384423
}

\begin{abstract}
Patient education is one way of communication between patient and nurses, which provides the necessary knowledge for enhancing patient care. The objective of this study was to identify the perception and factors influencing the practice of patient education among public hospital nurses. A total of 246 staff nurses were involved in this study. A self-administered questionnaire was used in this study. Findings indicated that lack of time, inadequate staffing and lack of knowledge were factors that influenced the practice of patient education. In conclusion, public hospital nurses were having a positive attitude towards patient education but could not practice completely.
\end{abstract}

Keywords: Patient education, nurses, practice

eISSN: 2398-42870 2020. The Authors. Published for AMER ABRA cE-Bs by e-International Publishing House, Ltd., UK. This is an open access article under the CC BYNC-ND license (http://creativecommons.org/licenses/by-nc-nd/4.0). Peer-review under responsibility of AMER (Association of Malaysian Environment-Behaviour Researchers), ABRA (Association of Behavioural Researchers on Asians) and cE-Bs (Centre for Environment-Behaviour Studies), Faculty of Architecture, Planning \& Surveying, Universiti Teknologi MARA, Malaysia.

DOI: https://doi.org/10.21834/ebpj.v5i15.2476.

\subsection{Introduction}

Nurses play many roles in healthcare, with one of the most essential and lasting functions is a nurse as a patient educator. Patient education is one of the nurse activities that increase an individual awareness regarding health to achieve better health and improve quality of life by giving information, teaching and learning activities to the individuals and communities (Yeh, Wu, \& Tung, 2018). Providing health education will help the individual to decide a health action. Nurses, as an educator, always been an example and guide the community. According to Adugbire and Aziato (2018), lack of communication gave the patient the perception that the nurses have limited time to talk, listen or be with them. Therefore, the nurses need to prepare themselves with various communication skills to provide adequate health education to patients. The relationship between nurses and patient is fundamental to the therapeutic partnership, where it is essential to show interest in patients' daily moods (Uno, Tsujimoto, \& Inoue, 2017). Nowadays, the number of rehospitalisation among discharged patients keeps increasing. Many patients return to the hospital quickly because of the lack of health education among nurses to patients regarding post-hospitalisation care during the discharge process. Without patient education, there is nearly no effective healthcare with enhancing the long-term result (Smith, \& Zsohar, 2013). An effort to improve the practice of nurses to educate the patients' needs to be implemented to overcome this problem. Understanding and enhancement need to be done to attract nurses to learn the importance of patient education in a nursing role. Also, communication between a patient and nurses provides the basis for enhancing patient care and potentially affecting health outcomes. By doing the exploration on the current patient education practice, perhaps to overcome the issue of hospital readmission and patient able to manage their activities of daily living after receiving effective

eISSN: 2398-42870 2020. The Authors. Published for AMER ABRA cE-Bs by e-International Publishing House, Ltd., UK. This is an open access article under the CC BYNC-ND license (http://creativecommons.org/licenses/by-nc-nd/4.0/). Peer-review under responsibility of AMER (Association of Malaysian Environment-Behaviour Researchers), ABRA (Association of Behavioural Researchers on Asians) and cE-Bs (Centre for Environment-Behaviour Studies), Faculty of Architecture, Planning \& Surveying, Universiti Teknologi MARA, Malaysia.

DOI: https://doi.org/10.21834/ebpj.v5i15.2476. 
patient education. This study aims is to explore the perception and practice of patient education among nurses in one of the public hospital in Malaysia.

\subsection{Literature Review}

Patient education is an essential component to develop a patient's knowledge, understanding, and preparedness (Bergh, Friberg, Personn \& Dahlborg-Lyckhage, 2015). Nurses nowadays know that giving an education to the patient is essential. Patient education plays a vital role in encouraging the patient to become more responsible for their health and illness. There are a few evidence shows that many patients wish to increase their knowledge and get a better understanding of the specific disease. However, some of them feeling not satisfied with the education given by nurses (Jamaati et al., 2014).

According to Pongthavornkamol, Khamkon, Phligbua, Cohen, and Botti (2018), patient participation in care is an essential component. Encourage patient to be involved in their care is a critical factor in improving the quality of care, reducing the risk that related to health care and upgrades health outcome. Also, a collaboration of effort in treatment between nurses and patient can reduce patient's symptoms and improve clinical outcomes. Provision of patient education has long been acknowledged as a critical responsibility of nurse and as fundamental to the empowerment of patients. Ensuring that patients are adequately informed is essential to promote the highest quality of care, safeguarding minimum standards of care and providing patient-centred care. It also has been found that patient education is a crucial aspect of patient satisfaction (Bennett et al., 2015).

Several studies by previous researchers have found that nurses' experiences, workplace culture, lack of time, heavy workload, the complexity of patients' condition, lack of educational preparation and insufficient staffing were factors influencing the practice of patient education. In addition, researchers mentioned that lack of information regarding the techniques and tactics of education and lack of recognition of patient's educational needs also might become factors influencing the practice of patient education (Oyetunde \& Akinmeye, 2015; Jones, 2010; Farahani et al., 2013). Another study was done by Uno et al. (2017) on factors affecting patient education from a cultural perspective mentioned that social and cultural factors influence patient education. Therefore, nurses must be aware of cultural issues in teaching process including religion, lifestyle, languages and social status of the patient. In addition, nurses also must respect the family's culture customs (Heidari \& Norouzadeh, 2013).

A study found that inadequate nursing practices cause nurses to be recognized as a technician that deliver only treatment, and the nursing profession is recognized negatively by the other health professionals and society (Calik, Aktas, Bulut, Anahar, \& Erdol, 2015). Researchers found that various factors influencing the patient education practice among nurses, including those issues related to management, working order, and human resources planning, work environment, nurse staffing, and nurse education appear to have significant effects on patient outcomes (Audet, Bourgault, \& Rochefort, 2018; Cho, Sloane, Kim, Kim, Sera, Choi, Yoo, Lee, \& Aiken, 2015). See, Chee, Rajaram, Kowitlawakul, and Liaw (2020), stated that patients have an improved understanding of how to provide self-care when they received effective patient education. To ensure effective patient education and methods that are individualized to the patient's level of health literacy and preferred method of teaching, the nurses must use specific approaches (Lasa-Blandon, Stasi, Hehir, \& Fischer-Cartlidge, 2019). Richard et al. (2018) have stated that how nurses involved in patient education is influenced by their level of educational preparation and workplace environments are contribute to maintaining their qualities of educational practice. According to Cho et al. (2015), nurse's level of education also will affect patient outcome. There is evidence that several patient mortality becomes low when the quantity of nurses with a bachelor's or higher degree is high (Cho et al., 2015; Bader et al., 2018; Audet et al., 2018).

\subsection{Methodology}

This study is a descriptive cross-sectional survey designed to collect information regarding the practice of patient education among nurses in one of the public hospital in Malaysia.

\subsection{Research Setting}

In 2019, data were collected from one of the public hospital in Selangor. The population for this study was selected among individuals who had some common characteristics; which in this study representing to staff nurses working in selected wards. The total populations of this study were 565 staff nurses included all nurses employed in the selected unit which are Medical, Surgical, Obstetric, and Gynaecological and Orthopaedic.

\subsection{Sample}

In this study, the population of registered nurses was $565(\mathrm{~N}=565)$ with the following characteristics: $35 \%$ Medical ward, 25\% Surgical ward, 24\% Orthopaedic ward and 16\% Obstetrics and Gynaecology ward. After the calculation of sample size by using Krejcie and Morgan's theory, a total numbers of 229 registered nurses were selected as a sample. This study only included the nurses from four areas that are Medical, Surgical, Orthopaedic and Obstetrics and Gynaecology.

\subsection{The Research Instrument}


The instruments that were used in this study for obtained data was a questionnaire adopted from Thoma (1999). This questionnaire was divided into three parts: Part A, Part B, and Part C. Part A are demographic data of participants, Part B is the perception of nurses towards patient education and lastly, Part $\mathrm{C}$ is the factors influence patient education.

\subsection{Sample Criteria}

The inclusion criteria for the study were registered nurse who are working in the selected ward; Medical, Surgical, Obstetrics and Gynaecology and Orthopaedic ward, registered nurses who understand Bahasa or English Languages, 18 years of age and over and providing ongoing care to the patient. While the exclusion criteria for the study were non-cooperative nurse who refused to fill the necessary information and registered nurses who are on medical leave, attending post basic, on unpaid leave or maternity leave.

\subsection{Procedure for Data Analysis}

The completed questionnaires were coded and subjected to statistical analysis using the IBM Statistical Package for the Social Sciences (SPSS) for Windows, version 21. The data were analyse and presented as descriptive data including frequency and mean.

\subsection{Findings}

The characteristics of each participant that are involved in this study are analysed by descriptive analysis. Data were obtained from the self-administered questionnaire, the overall response rate for this study was $99 \%$ which a total 250 set questionnaires were distributed and 246 nurses $(n=246)$ completed this questionnaire. There were from four departments which are from Medical, Surgical, Orthopaedic, Obstetric and Gynaecological ward. All the demographic data were presented in Table 1.

Most of the participant's age was range from 25 to 34 years' old which were $172(69.9 \%)$. The following percentage of participants' age under 25 years old was 38 (15.4\%) followed by participants' between 35 to 44 years old with $31(12.6 \%)$. Then, the lowest percentage was $5(2.0 \%)$ which showed the participants from the age above 45 years old. The number of participants that were participated in this study was dominated by females $227(92.3 \%)$. These proportions are similar to the ratio of females to males in the general nursing population.

The length of the registered nurses' experience in nursing was also collected. The highest percentage of participants' work experience was less than 3 years were $82(33.3 \%)$. The percentage of participants between 3 to 5 years' experience was $72(29.3 \%)$. Followed with the $62(25.2 \%)$ of participants that work experience 5 to 10 years. The lowest percentage was $30(12.2 \%)$ which was for the participants that work experience above 10 years. Majority of the nurses with a percentage of $235(95.5 \%)$ held a diploma in nursing, with another $11(4.5 \%)$ holding a degree in nursing.

The participant was also asked to indicate their primary area of practice. The participant who works in the medical ward was 86 $(35.0 \%)$. The surgical ward showed $64(26.0 \%)$. Then, followed by from orthopaedic ward and obstetrics and gynaecology ward with 62 $(25.2 \%)$ and $34(13.8 \%)$ respectively.

Registered nurses were also requested to indicate how much time they spend in patient education activities each day. Of the 246 participants to this item, most of the participants spend time with patient for patient education was 1 hour or less with $171(69.5 \%)$. The spend time between 2 to 3 hours was $56(22.8 \%)$. The lowest percentage for a total hour of spend time with patient for patient education was between 4 to 5 hours and above 6 hours was $11(4.5 \%)$ and $8(3.3 \%)$ respectively.

Table 1. Demographic Characteristics of Staff Nurses $(\mathrm{N}=246)$

\begin{tabular}{|c|c|c|}
\hline Demographic Characteristics & Frequency & Percent (\%) \\
\hline \multicolumn{3}{|l|}{ Age } \\
\hline Under 24 years old & 38 & 15.4 \\
\hline $25-34$ years old & 172 & 69.9 \\
\hline 35-44 years old & 31 & 12.6 \\
\hline 45 years or older & 5 & 2.0 \\
\hline \multicolumn{3}{|l|}{ Work Experience } \\
\hline $0-3$ years & 82 & 33.3 \\
\hline 3-5 years & 72 & 29.3 \\
\hline $5-10$ years & 62 & 25.2 \\
\hline$>10$ years & 30 & 12.2 \\
\hline \multicolumn{3}{|l|}{ Gender } \\
\hline Male & 19 & 7.7 \\
\hline Female & 227 & 92.3 \\
\hline
\end{tabular}




\begin{tabular}{|c|c|c|}
\hline \multicolumn{3}{|l|}{ Level of Education } \\
\hline Diploma & 235 & 95.5 \\
\hline Degree & 11 & 4.5 \\
\hline \multicolumn{3}{|l|}{ Area } \\
\hline Medical Ward & 86 & 35.0 \\
\hline Obstetrics/Gynaecology Ward & 34 & 13.8 \\
\hline Surgical Ward & 64 & 26.0 \\
\hline Orthopaedic Ward & 62 & 25.2 \\
\hline \multicolumn{3}{|l|}{ Hours } \\
\hline 1 hour or less & 171 & 69.5 \\
\hline $4-5$ hours & 11 & 4.5 \\
\hline $2-3$ hours & 56 & 22.8 \\
\hline 6 hours or greater & 8 & 3.3 \\
\hline
\end{tabular}

\subsection{Perceptions of staff nurses regarding patient education practice}

The overall results of the nurses' survey responses were utilized. The nurses agreed that they should assume the responsibility of coordinating patient education. The top three questions that most of the participants answered "agree" were; other disciplines need to be more involved in patient education; the nurse should assume the responsibility for coordinating patient education, and lack of time is a factor why documentation of patient education is not done with. The least three questions that most of the participants answered "agree" were; there is an adequate number of nurses to do patient education; there is sufficient time to do patient education, and there is an adequate number of nurses to do patient education (Table 2).

Table 2. Staff Nurses Perceptions towards Patient Education

\begin{tabular}{|c|c|c|}
\hline & Item & Mean \\
\hline 1 & Other disciplines need to be more involved in patient education. & 4.23 \\
\hline 2 & The nurse should assume the responsibility for coordinating patient education. & 4.16 \\
\hline 3 & Lack of time is a factor why documentation of patient education is not done. & 4.16 \\
\hline 4 & $\begin{array}{l}\text { There are adequate patient education materials available for nurses to utilize } \\
\text { when doing patient education. }\end{array}$ & 2.87 \\
\hline 5 & There is adequate time to do patient education. & 2.82 \\
\hline 6 & There is an adequate number of nurses to do patient education. & 2.61 \\
\hline
\end{tabular}

\subsection{Factors Influence Practice of Patient Education among Nurses}

The study identified some factors that influenced the practice of patient education among the nurses. Findings indicated that the top three barriers to patient education were; lack of time (72.8\%) with 179 participants, inadequate staffing (13.4\%) with 33 participants and lack of knowledge (6.1\%) with 15 participants (Table 3). It was interesting to note that no one of nurses selected no responsibility for teaching or lack of enjoyment in patient education as barriers. Similar results with Farahani et al. (2013) revealed that lack of time as the main barrier to do the patient education because nurses have their own task besides doing the patient education. Limited knowledge of nurses also influenced the practice of patient education.

Table 3 Identified Barriers to Patient Education ( $\mathrm{N}=246)$

Frequency $\quad$ Percent $(\%)$




$\begin{array}{lcc}\text { Lack of time. } & 179 & 72.8 \\ \text { Lack of knowledge. } & 15 & 6.1 \\ \text { Inadequate staffing. } & 33 & 13.4 \\ \text { Unavailability of resource material. } & 9 & 3.7 \\ \text { Low priority to a nursing task. } & 1 & 0.4 \\ \text { Environment non-conducive to teaching. } & 6 & 2.4 \\ \text { Not my responsibility. } & 0 & 0 \\ \text { Patient education not enjoyable. } & 0 & 0 \\ \text { Patient not receptive to teaching. } & 1 & 0.4 \\ \text { Other. } & 2 & 0.8\end{array}$

\subsection{Discussion}

Most of the nurses perceived patient education as a high priority in nursing care and it was nursing responsibility to provide patient education. Based on this study, most of the nurses agreed that other healthcare provider also need to be more involved in patient education and give a cooperation to increase patient knowledge. Result from this study identified that nurses' working experience and level of education determine the priority staff nurses placed on patient education practice. However, age, gender, working area and total time they spend in patient education did not determine the staff nurses priority for patient education practice.

\subsection{Nurses Perception Regarding the Patient Education Practice}

The results of this studies have shown that most of the nurses perceived patient education as a high priority in nursing care and it was nursing responsibility to provide patient education. Similar with the study done by Khuan and Juni (2017), that also found that the nurses know that they had to perform a good communication skill with the patient to reduce patient's anxiety and feeling isolation during hospitalization. Furthermore, in another research study also revealed that providing patient education is also one of the critical nursing cares. A nurse must spend more time teaching the patient to achieve the best outcomes for their patient. (Smith \& Zsohar, 2013; Richard et al., 2018). Based on the studies, the nurses feel that they would not have a hard time in providing the patient's education and their attitudes were positive as they have received guidelines and training about how to provide the patient education and they are confident in getting the review about their teaching and learning technique from the in-service.

Most of the nurses also agree that health education can become more active and have more good quality if the supervisor or the head nurse emphasizes the importance of patient education through formal or informal classes to the nurses. For example is continuous nursing education (CNE). Moreover, the supervisor or the head nurse giving the review regarding the teaching technique for every nurse. However, according to Seyedin et al. (2015), in most researches, the role of senior manager and their participation in patient education has been neglected. The nurses believe that getting evaluation can make them acknowledge and recognize their teaching ability and help them to increase their knowledge and skill.

\subsection{Factors Influencing the Practice of Patient Education among Nurses}

Most of the nurses believe that there are two categories of factors which are those related to the nurses themselves and those related to their working environment. They believe that those reasons are the main causes that lead to the weakening of their educational performance. The factors that related to the nurses that considered in this study was time spent with the patient regarding the patient education, nursing activity itself, responsibility of identifying the patient's needs, limited knowledge of the nurses, identifying the barriers to patient education and lastly identifying the facilitator for patient teaching.

This study shows that the number of nurses that chose to do informal teaching is approximately six times higher than the number of nurses that chose to do the formal teaching. This is because informal teaching is easier and casual for the nurses as they do not have to free their time for an appointment for the patient education instead of the nurses can provide the patient education while they give treatment or routine procedure to the patient at their bedside. Similar factors stated in other studies that informal, fast delivery instructions are common methods for nurses to educate patients, emerging as a mean to deliver critical information to patients in a timely and costeffective manner (Dunn \& Milheim, 2017). Meanwhile, formal teaching needs to be a more serious and detail explanation regarding the patients' disease. As stated by Sayin and Aksoy (2012), patient preferred the information to be printed and use simple word to explain because medical jargon made it hard to understand the information content. Most of the patient suggested that providing both oral presentation and written information to enhance patient understanding (Horstman et al, 2017). 
The study result indicates that the majority of the nurses' perception that having a lot of nursing care and treatments causing the nurses to abandon their task to provide the patient education. Meanwhile, the minority of the nurses which are three participants have chosen assessment as their one of the main reasons why they could not provide the patient education to their patients. The previous study done by Khuan and Juni (2017) revealed that the nurses think that health education is the least significant of their responsibility due to busy nursing task such as pass over the report, serving medication and other nursing care are way more important and they have to give more attention to the patient which needs the treatments and their nursing care more compared to the patient education as most of the patients have their own understanding towards their disease.

The other factors that influenced the patient education practice is the limited knowledge of the nurses. When the nurses lack knowledge regarding patient education, the majority which is 142 participants have chosen that they will gain the knowledge to do the teaching. This result is supported by Oyetunde and Akinmeye (2015), knowledge of patient education and its practice are associated. This may be because by gaining new knowledge, their understanding regarding the topic will increase and also can broaden their outlook and give a new point of view thus increase their self-confidence level. Therefore, they could help more patients in understanding the topic.

\subsection{Conclusion and Recommendation}

In conclusion, this study has revealed that lack of time, inadequate staffing and lack of staff nurse's knowledge were the important factors that influenced the practice of patient education. Findings from this study revealed that most of the nurses perceived patient education as a high priority in nursing care and it was nursing responsibility to provide patient education. In addition, nurses' working experience determined the priority staff nurses placed on patient education while working area did not determine the staff nurse's priority for patient education; the educational qualifications of nurses influenced the perception of patient education among nurses.

Nurses should be actively involved in established an effective patient education, as they acknowledge the important of patient education. Nurse Manager should encourage their nurses to practice patient education by revising the nurses' busy schedule, arranging the staff on duty and allow the nurses to upgrade their knowledge. A future study is suggested to explore the nurses and patients experienced of the patient education conducted in various public hospital in Malaysia. Further study on the relationship between the nurse education level and their practice of nursing care also could be investigated.

\section{Acknowledgement}

We thank the participants who participated and spending their time in this study and UiTM Grant (Project number 5/3LESTARI (222/2017)

\section{Paper Contribution to Related Field of Study}

The result of this study perhaps could be used to enhance the patient education practice among nurses and give the better view to develop a structure patient teaching.

\section{References}

Audet, L., Bourgault, P., \& Rochefort, C. M. (2018). Associations between nurse education and experience and the risk of mortality and adverse events in acute care hospital: A systematic review of observational studies. International Journal of Nursing Studies, 80, 128-146. doi: 10.1016/j.jnurstu.2018.01.007

Adugbire, B. A., \& Aziato, L. (2018). Surgical patients' perspectives on nurses' education on post-operative care and follow up in Northern Ghana. BMC Nursing, 17(1). doi:10.1186/s12912-018-0299-6

Bergh, A. L., Persson, E., Karisson, J., Friberg, F. (2014). Registered nurses' perceptions of conditions for patient education - focusing on aspects of competence. Scandinavian Journal of Caring Science, 283(3), 523-536.

Calik, K. Y., Aktas, S., Bulut, H. K., Anahar, E. O., \& Erdol, H. (2015). Are the nurses able to reflect their undergraduate education upon the clinic? The effect factor. Procedia - Social and Behavioral Sciences, 186, 143-150. doi: 10.1016/j.sbspro.2015.04.073

Cho, E., Sloane, D. M., Kim, E. Y., Kim, Sera., Choi, M., Yoo, Y. I., Lee, H. S., \& Aiken, L. H. (2015). Effects of nurse staffing, work environments, and education on patient mortality: An observational study. International Journal of Nursing Studies, 52, 535-542. doi: 10.1016/j.jinurstu.2014.08.006

Dunn, P. J., \& Milheim, K. L. (2016). Enhancing informal patient education in nursing practice: A review of literature. Journal of Nursing Education and Practice, 7(2). doi: http://dx.doi.org/10.5430/jnep.v7n2p18

Farahani, M. A., Mohammadi, E., Ahmadi, F., \& Mohammadi, N. (2013). Factors influencing patient education: A qualitative research. Iran J Nurs Midwifery Res, 18(2), 133-139.

Heidari, M. R. and Norouzadeh, Reza. (2013). Factor affecting patient education from cultural perspectives. J. Adv Med\&Prof, 1(4), 136-139. 
Horstman, M., Mills, W. L., Herman, L. I., Cai, C., Shelton, G., Qdaisat, T., Berger, D. H., \& Naik, A. D. (2017). Patient experience with discharge instructions in postdischarge recovery: a qualitative study. BMJ Open, 7(2). doi: http://dx.doi.org/10.1136/bmjopen-2016-014842

Jamaati, H., Kashafi, M. B., Vahedian-Azimi, A., Asghari-Jafarabadi, M., Avazeh, A., \& Hashemian, S. M. R. (2013). Patient education problems in clinical and educational settings: A review and mixed methods study. International Journal of Medical Reviews, 1 (3), 133-141.

Jones, R. A. (2010). Patient education in rural community hospitals: Registered nurses' attitudes and degrees of comfort. The Journal of Continuing Education in Nursing, 41 (1). doi: 10.3928/00220124-20091222-07

Khuan, L., \& Juni, M. H. (2017). Nurses' opinions of patient involvement in relation to patient-centred care during bedside handovers. Asian Nursing Research, 11, 216222. doi: 10.1016/j.anr.2017.08.001

Lasa-Blandon, M., Stasi, K., Hehir, A., \& Fischer-Cartlidge, E. (2019). Patient Education Issues and Strategies Associated With Immunotherapy. Seminars in Oncology Nursing, 35(5). doi:https://doi.org/10.1016/j.soncn.2019.08.012

Oyetunde, M. O., \& Akinmeye, A. J. (2015). Factors influencing practice of patient education among nurses at the University College Hospital, Ibadan. Open Journal of Nursing, 5, 500-507. doi: 10.4236/ojn.2015.55053

Pongthavornkamol, K., Khamkon, A., Phligbua, W., Cohen, E., \& Botti, M. (2018). Thai oncology nurses' perceptions of patient participation in acute cancer care. Asian Nursing Research, 12, 209-215. doi: 10.1016/j.anr.2018.08.004

Richard, E., Evans, T., \& Williams, B. (2018). Nursing students' perceptions of preparation to engage in patient education. Nurse Education in Practice, 1 (6). doi: 10.1016/j.nepr.2017.09.008

Sayin, Y., \& Aksoy, G. (2012). The nurses's role in providing information to surgical patients and family members in Turkey: a descriptive study. AORN J, 95(6), $772-87$. doi: 10.1016/j.aorn.2011.06.012

See, M. T., Chee, S., Rajaram, R., Kowitlawakul, Y., \& Liaw, S. Y. (2020). Missed nursing care in patient education: A qualitative study of different levels of nurses' perspectives. Journal of Nursing Management, 28(8), 1960-1967. doi:10.1111/jonm.12983

Seyedin, H., Goharinezhad., S., Vatankhah, S., Azmal, M. (2015). Patient education process in teaching hospital of Tehran University of Medical Sciences. Med J Islam Repub iran, 29, 220 .

Smith, J. A., \& Zsohar, H. (2013). Patient-education tips for new nurses. Nursing 2013, 43(10), 1-3. doi: 10.1097/01.NURSE.0000434224.51627.8a

Uno, M., Tsujimoto, T., \& Inoue, T. (2017). Perceptions of nurses in Japan toward their patients' expectations of care: A qualitative study. International Journal of Nursing Science, 4(1), 58-62. Retrieved from https://doi.org/10.1016/j.jpss.2016.12.005

Yeh, M. Y., Wu, S. C., \& Tung, T. H. (2018). The relation between patient education, patient empowerment and patient satisfaction: A cross-sectional-comparison study. Applied Nursing Research, 39, 11-17. doi: 10.1016/j.apnr.2017.10.008 